\title{
The Effects of Service-Based Learning on Meta-Cognitive Strategies During an Engineering Design Task
}

\author{
Gay Lemons \\ Department of Psychology \\ University of Massachusetts, Lowell \\ lemo5876@yahoo.com \\ Chris Swan \\ Department of Civil \& Environmental Engineering \\ Tufts University \\ chris.swan@tufts.edu
}

\author{
Adam Carberry \\ Department of Engineering \\ College of Technology \& Innovation \\ Arizona State University \\ adam.carberry@asu.edu \\ Linda Jarvin \\ Paris College of Art \\ Paris, France \\ linda.jarvin@parsons.paris.edu
}

Abstract - Service-Based Learning (SBL) has become an emerging pedagogical tool for engineering education. Although there is a large body of literature reporting the benefits of SBL activities, most studies have relied on self-report measures and generalized learning contributions. Our evaluation went beyond self-perceptions by investigating what effects, if any, SBL activities had on the metacognitive processes of students during an engineering design task. Verbal protocols were collected from ten engineering students during an openended, model-building design task. The five SBL students and five non-SBL students also completed post-task interviews and reflection papers. The students in our sample who had participated in SBL activities voiced more metacognitive phrases, demonstrated more accurate task analysis and clearer strategic planning skills, were more skilled at discriminating useful from superfluous information, and had a better understanding of clients' needs and constraints.

Index Terms - engineering design, service-based learning, verbal protocol analysis, metacognition, self-regulated learning

\section{INTRODUCTION}

ABET (formerly the Accreditation Board for Engineering and Technology ${ }^{1}$ ) states in their list of course outcomes and requirements that all engineering graduates should understand the impact of engineering in a global and societal context. One movement to address engineering stewardship has been the development of service-based learning courses and programs.

Service learning has been defined as an activity that integrates academic subject matter with service to a community that helps foster civic responsibility and strengthens communities ${ }^{2-6}$. Although some researchers ${ }^{5}$ consider academic credit a necessary component of service learning, Jacoby $^{7}$ defined service learning simply as experiential-based activities designed to promote learning through engagement in real life opportunities that address the needs of a community. For the purpose of this paper, the term service-based learning (SBL) will be used to encompass the broader perspective which includes non-credit bearing and extracurricular learning experiences. 
Regardless of the setting, all authentic SBL experiences have common characteristics. Service-based learning is more likely to be personally meaningful to participants, addresses complex problems in complex settings rather than simplified problems in isolation, offers opportunities to engage in problem-solving and critical thinking, requires participants to gain knowledge of the specific context and community challenges surrounding their SBL activity, and involves cooperative rather than competitive experiences ${ }^{8}$.

The non-competitive aspect is a critical component of SBL activities. Jacoby ${ }^{7}$ emphasized the importance of fostering a symbiotic, non-hierarchical relationship between the service provider and the group being served by providing opportunities for each group to be both teacher and learner. This means that the assets of all parties involved should encourage a synergy of collaboration, mutual responsibility, joint decision-making, reciprocity, and diversity in order to feel a sense of ownership in the project ${ }^{9-11}$.

Public service in academia has grown dramatically in recent decades as increasing numbers of institutions of higher education include SBL activities in their curriculum ${ }^{12}$. The growth of interest in promoting SBL activities specifically within engineering is evidenced by organizations such as Engineering Projects in Community Service (EPICS) ${ }^{13}$, Engineers for a Sustainable World $(E S W)^{14}$, Engineers Without Borders $(E W B)^{15}$, Service Learning Integrated throughout a College of Engineering $(\mathrm{SLICE})^{16}$, and Student Teacher Outreach Mentorship Program (STOMP) $)^{17}$.

The popularity of SBL programs has generated a growing body of literature investigating this pedagogical method. Research results are often couched in general terms, generated from student self-report measures or observations from supervising faculty. There is a dearth of literature looking at specific measures, particularly in the area of cognitive skill development during a design task.

The purpose of this research was to go beyond self-perceptions by investigating what effects, if any, SBL had on the cognitive processes of engineering students during a design task. For the purpose of this paper, cognitive processes refer to the mental processes or strategies used to select, store, retrieve, encode, and process information. These processes inform decision making and problem solving. An engineering design task was chosen because solving welldefined problems in the classroom does not readily transfer to solving complex, ill-defined problems in the workplace, as the former requires cognitive and metacognitive processes that are insufficient for solving the latter ${ }^{18 .}$

We compared the cognitive strategies of SBL and non-SBL students during a hands-on, model building design task to answer our research question:

Are there differences in cognitive processes between SBL and non-SBL students during an engineering design task? If so, what are the differences? 


\section{LITERATURE REVIEW}

There have been numerous studies reporting how SBL activities address ABET Criterion 3a-k such as (a) an ability to apply knowledge of mathematics, science, and engineering, (b) an ability to critically analyze and interpret data, (c) an ability to design under constraints (d) an ability to function on multi-disciplinary teams (e) an ability to identify, formulate, and solve engineering problems, (f) an understanding of professional and ethical responsibility (g) an ability to communicate effectively, and (j) gain knowledge of contemporary issues. These studies have reported that students who participated in SBL activities have:

- a lower transfer/dropout rate in engineering disciplines compared to students not so involved.

- a greater ability to work more cooperatively in teams.

- advanced leadership skills and communication skills.

- a more concrete understanding of basic engineering design principles.

- the ability to be innovative and resourceful when confronted with illstructured problems, unforeseen challenges, and conflicting information.

- the ability to interact with a broader range of socioeconomic classes.

- enhanced critical thinking and project planning skills.

- increased self-efficacy and confidence.

- a new passion and motivation for vocations within engineering.

- increased awareness of their potential to make an impact.

- a better understanding of how problems are socially embedded, reducing stereotyping and prejudicial perspectives.

- a higher percentage of women participants in relation to the percentage of women in engineering overall $2,10,12,19-26$.

The positive effects of SBL activities have been attributed to processing the experience through reflection, discussions, and interactions with other students and faculty. The opportunities to clarify, elaborate, evaluate, justify, and consider alternatives through dialogue with others were powerful components of SBL activities ${ }^{8,10,12,24}$.

\section{THEORETICAL FRAMEWORK}

The benefits gained through SBL have been primarily attributed to the processing of SBL experiences through reflection. Based on this finding, we chose to look at the design process of engineering students through the lens of metacognitive and self-regulated learning theories. The construct of metacognition was recognized by Flavell over thirty years ago and is defined as the knowledge and awareness of one's own thinking ${ }^{27-29}$. Metacognition is our ability to reflect on, monitor, strategize, and evaluate our learning and the information known to us. Metacognitive knowledge includes knowing general strategies for learning and problem solving, knowing what knowledge one already has, and knowing the conditions necessary for learning new information.

Self-regulated learning is the process involved in the monitoring and regulation of knowledge building. It involves setting goals, adopting strategies for attaining those goals, monitoring progress, reflecting on and evaluating methods, and restructuring as necessary. 
Metacognition promotes self-regulation. Students self-regulate their learning when they are aware of their own learning process ${ }^{28-31}$.

Students with effective metacognitive skills can accurately estimate their knowledge and regulate their thoughts and behaviors in order to set strategies, achieve goals, and develop effective plans for new learning. They are aware of the effectiveness of their strategies and can adapt accordingly. Without effective regulation, students may not use the knowledge they have, or properly apply it to the task at hand ${ }^{32}$. Academically able students have higher metacognitive abilities than those less able ${ }^{33}$. Although conceptual and procedural knowledge are important, effective metacognitive strategies play a crucial role in how well learners learn and are needed to support more advanced conceptual knowledge ${ }^{34}$.

Self-regulatory processes consist of three cyclical phases: forethought, performance, and self-reflection. The forethought phase involves task analysis, strategic planning, and goal setting. Specific and proximal goals enhance outcomes better than general and distal goals ${ }^{35}$. More naïve self-regulators who tend to set nonspecific, distal goals are unsure as to what to do next, must wait longer for corrective feedback, and are more easily discouraged by seemingly slower progress 36,37 .

The performance phase refers to the deployment of specific strategies as well as selfobservation. The self-reflection phase includes self-evaluation, and comparing performance with goals $^{35,36}$. Zimmerman ${ }^{36}$ considered self-reflective practice, "perhaps the most important performance control process that distinguishes skillful from naïve self-regulators” (p. 8). Selfreflection involves keeping track of one's effectiveness as one performs and using the information to alter performance. Naïve self-regulators fail to monitor their performance or monitor haphazardly. This often leads to a reliance on guessing due to incomplete or fragmentary information or misinterpreting the information they do have. We investigated some of these cognitive processes of engineering students during a hands-on, model building design task.

\section{RESEARCH METHOD}

A simple design task was created to explore possible differences in cognitive processes between SBL and non-SBL students during an engineering design task. Verbal Protocol Analysis (VPA) was used to collect data as it is considered the most appropriate method to study the cognitive abilities and processes of designers ${ }^{38-41}$. VPA has been used extensively since the 1970's to study the cognitive processes of engineering students ${ }^{38,42-45}$ as well as experienced designers ${ }^{39,46-48}$. Although VPA is the most suitable method for documenting cognitive processes, it is not an assessment tool appropriate for large subject populations because of the copious amount of time required for analysis.

During VPA, our subjects were asked to continually think aloud while performing a design $\operatorname{task}^{49,50}$. Subjects were asked to report the contents of their working memory, so that their verbalized thought processes could be captured on videotape and later transcribed. The texts were then coded and analyzed, which provided our main source of data. These verbal reports offered insights into how subjects generated and transformed information about the problem and how they went about developing a solution.

After completing the design task, additional data was collected via individual open-ended interviews in order to expand on the verbal protocol data and to better understand participants' cognitive processes. Interviews are considered a mode of systematic inquiry and one of the most powerful ways of obtaining rich, experiential accounts of events from others ${ }^{51,52}$. After the 
interview, participants were asked to write a short reflection paper of their design project, focusing on their design experience and how they came up with their prototype design.

\section{Participants}

Engineering students attending a private university in the northeastern United States were solicited to participate in an engineering design task. Specific recruitment of SBL students was implemented through the relationship between the authors and campus programs. The second author was director of the STOMP program at this institution and the third author coordinates and supervises EWB projects. The final sample of ten students consisted of six males and four females from different academic years and diverse engineering disciplines. One female and four males had been involved in SBL activities.

Students were coded according to gender ( $M=$ male, $F=$ female), engineering discipline (e.g., $M E=$ mechanical engineering, $C h E=$ chemical engineering), undergraduate class level $(2=$ sophomore, 3 = junior, $4=$ senior), and $s$ for those with SBL experiences. Since there were two students identified as $M-M E-4-s$, the student with five semesters of SBL experience was designated $M-M E-4-s-5$ (See Table I).

TABLE I

STUDENT PARTICIPANTS

\begin{tabular}{lclcc}
\hline $\begin{array}{l}\text { Participant } \\
\text { Code }\end{array}$ & Gender & Engineering Discipline & $\begin{array}{l}\text { Class Level } \\
\text { (undergrad) }\end{array}$ & $\begin{array}{l}\text { \# Semesters/ } \\
\text { Type of SBL } \\
\text { experience }\end{array}$ \\
\hline M-ME-4-s & M & Mechanical Engineering & 4 & 1/EWB \\
M-ME-4-s-5 & M & $\begin{array}{l}\text { Mechanical Engineering } \\
\text { Environmental }\end{array}$ & 4 & 5/STOMP \\
F-EnE-4-s & F & Engineering & 4 & 6/STOMP \\
M-EE-3-s & M & Electrical Engineering & 3 & 4/STOMP \\
M-ChE-2-s & M & Chemical Engineering & 2 & 2/EWB \\
F-CE-4 & F & Civil Engineering & 4 & 0 \\
F-ME-4 & F & Mechanical Engineering & 4 & 0 \\
M-GE-4 & M & General Engineering & 4 & 0 \\
M-ME-3 & M & Mechanical Engineering & 3 & 0 \\
F-ME-3 & F & Mechanical Engineering & 3 & 0
\end{tabular}

In addition to being at different stages in their educational careers, participants had varying levels of design experience. Design courses for students in any of the engineering programs at this institution are not required until the senior year. However, some students may have taken elective courses, summer internships, or participated in extracurricular activities where they may have been exposed to the design process. While the range of previous design experience within this student sample varied, those with SBL experiences did not, as a group, have more design experience than the non SBL students. 


\section{Procedure}

The study participants were solicited directly via e-mail. Each student who consented to participate was tested individually in a small conference room on campus. A small audio-video camera was mounted on the ceiling to record speech as well as students' hand movements. At the beginning of the activity, participants were told that the purpose of the study was to investigate problem-solving strategies during a design task. Participants were instructed to constantly verbalize what they were thinking as they proceeded through the design task. A practice thinkaloud project of assembling a 24-piece puzzle was given to the students to familiarize them with the process. When the subjects finished the puzzle, they were given an information sheet that explained the design task: To design and build a jar opener for individuals with the use of only one hand. A more detailed description of the procedure can be found in a previous publication ${ }^{53}$.

Each participant was presented with a choice of 15 task-specific activities. The activities were titled: (1) Talk to Jim (an amputee), (2) Speak with Mary (a stroke victim), (3) Learn about amputees, (4) Learn about stroke, (5) Look at other models, (6) Plan/draw/sketch, (7) View available materials, (8) Read technical descriptions of prototype jar openers, (9) Build a prototype, (10) Review first principles of physics, (11) Talk to jar manufacturers, (12) Examine elementary mechanics, (13) Look at jar variables, (14) Investigate aesthetic options, and (15) View unnecessary nonsense.

These activities were presented to the participants using physical sets of cards laid out on a large table. Each activity had five to eight cards that offered various pieces of information. The instruction sheet explained that participants could choose whichever activities they thought might help them in formulating a solution. All activities contained cards with superfluous information to see if participants could filter out the unnecessary information.

When subjects chose the Build a Prototype activity, they were handed a kit of LEGO ${ }^{\circledR}$ pieces along with a twist top jar to use as a test jar for their prototype. The participants were instructed to use the $\mathrm{LEGO}^{\circledR}$ pieces to build their prototype and to not be overly concerned with any usability challenges arising from the materials. While the functionality of the pieces did not allow for heavy force to be used in opening a jar, the fact that the pieces could be assembled, taken apart, and reassembled quickly and easily outweighed this disadvantage. In addition, due to their long-standing popularity, most students are at least somewhat familiar with LEGO ${ }^{\circledR}$ pieces.

While the participants performed the design task, two researchers (the first two authors) took observational notes. If participants became silent, they were prompted by one of the researchers to continue thinking aloud. The individual sessions lasted between 32 to 80 minutes with most of the participants taking approximately an hour to complete the task. When finished with the design task, each student was interviewed for approximately 15 minutes to gain further insights regarding their problem solving process. Students were also asked to write a short reflection paper about their design process during this task. All of the participants wrote one to two short paragraphs.

The recorded sessions and interviews were transcribed and initially coded by the first author. Codes were later checked by the second author and reviewed by two outside coders not directly involved with this research project. Each participant was sent their coded transcript and asked to comment on the accuracy of our translation and codes. This member checking was included as an element of triangulation to strengthen confirmation of our interpretations ${ }^{54}$. While some of the students made a few clarifying comments, most concurred with how their thoughts and words were interpreted. 


\section{DATA ANALYSIS}

The transcribed texts of the verbal protocols and interviews formed the main data for analysis. Comments from the reflection papers were incorporated and used as supporting data. Content analysis $^{54,55}$ of these verbal protocols was employed using HyperResearch TM (by ResearchWare), a qualitative data software package that helps organize and keep track of large amounts of verbal data. This form of analysis involves manually searching through text for recurring words, phrases, or themes. Emergent patterns and themes defined the categories or codes. Some phrases were coded for multiple categories. Once categories were created, constant comparison was employed to ensure internal homogeneity and external heterogeneity of the categories $^{54}$. Internal homogeneity concerns cohesiveness, or the extent to which each entry within a category was similar to every other entry in that category in a meaningful way. External heterogeneity concerns independence, or the extent to which differences between categories are distinct and clear. To ensure objectivity, numerous sessions and lengthy discussions with two outside coders were conducted to achieve $100 \%$ inter-rater consensus. Eleven categories derived from our data (See Table II).

TABLE II

CATEGORIES DERIVED FROM THE DATA

\begin{tabular}{|c|c|c|}
\hline Category & Code & Description \\
\hline Idea Generation & Idea Gen & Formulates, explains, or discusses their plan, idea, or concept. \\
\hline Evaluates & Eval & $\begin{array}{l}\text { Makes some sort of judgment or assessment of a prototype, their drawing, } \\
\text { model, or idea. }\end{array}$ \\
\hline $\begin{array}{l}\text { Metacognitive } \\
\text { Strategies }\end{array}$ & Meta Cog & $\begin{array}{l}\text { Is aware of their own knowledge building, knowledge searching, or } \\
\text { organizational strategies. }\end{array}$ \\
\hline $\begin{array}{l}\text { Describes } \\
\text { Information }\end{array}$ & Desc Info & $\begin{array}{l}\text { Describes the prototypes, jars, or materials or is reading pieces of information } \\
\text { from the cards. }\end{array}$ \\
\hline $\begin{array}{l}\text { Discriminates } \\
\text { Information }\end{array}$ & Disc Info & Is able to discern important information from insignificant information. \\
\hline $\begin{array}{l}\text { Clarifies } \\
\text { Information }\end{array}$ & Clar Info & Reiterates some fact or brings a piece of information to attention. \\
\hline $\begin{array}{l}\text { Refers to the } \\
\text { Client }\end{array}$ & Refer Client & Makes a reference to the client or the client's needs. \\
\hline Miscellaneous & Misc & Phrases relating to design or building that do not fit into any other category. \\
\hline $\begin{array}{l}\text { LEGO } \\
\text { Limitations }\end{array}$ & LEGO Limit & Expresses the challenges of building with LEGO pieces. \\
\hline Confusion & Conf & $\begin{array}{l}\text { Expressed poor comprehension of facts, was not clear about explicitly stated } \\
\text { information. }\end{array}$ \\
\hline $\begin{array}{l}\text { Other } \\
\text { Categories }\end{array}$ & Other Cat & $\begin{array}{l}\text { Categories that were strong enough to create for some individuals but did not fit } \\
\text { every participant. For example, some participants had numerous phrases } \\
\text { regarding testing the model. But the category of "Testing Model" was not strong } \\
\text { enough across participants to warrant keeping it as an independent category. In } \\
\text { addition to the "Test Model" category, the other categories were: Global } \\
\text { Perspective, Kinesthetics, Opportunistic Behavior, and Personal Experience. }\end{array}$ \\
\hline
\end{tabular}




\section{RESULTS}

All of the categorized phrases were totaled (Total \# Phrase) in order to calculate the percentage of phrases uttered in each particular category (See Table 3). As can be seen in Table III, most of the students had roughly the same number of phrases in Idea Generation, Evaluation, Describing Information, and Clarifying Information. The average time between the groups to complete the task differed by only five minutes and the difference in the average number of phrases between the groups reflected this slight time difference. The categories in which there are larger observed differences between the two groups will be discussed in the subsequent sections: Metacognitive Strategies, Confusion, and Discriminates Information.

TABLE III

Percentages of CATEgories by PARTICIPATION (SBL/NON-SBL)

\begin{tabular}{|c|c|c|c|c|c|c|c|c|c|c|c|c|c|}
\hline 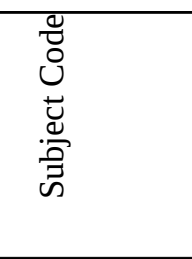 & 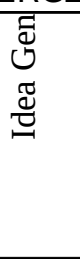 & 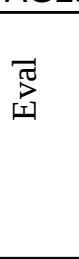 & 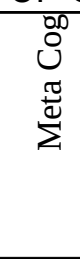 & $\begin{array}{l}0 \\
\stackrel{O}{\Xi} \\
u \\
\mathscr{U} \\
0\end{array}$ & 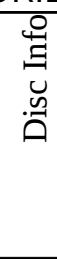 & 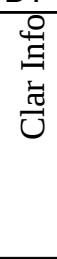 & 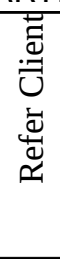 & $\stackrel{\mathscr{n}}{\dot{Z}}$ & 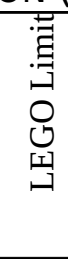 & ô & 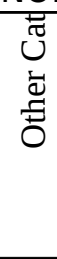 & 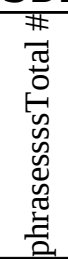 & 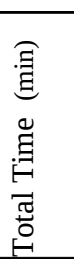 \\
\hline M-ME-4-s-5 & 30 & 28 & 13 & 9 & 7 & & 2 & 4 & 6 & & & 190 & 62 \\
\hline F-EnE-4-s & 31 & 21 & 16 & 9 & 2 & 2 & 12 & 4 & 2 & & 2 & 173 & 65 \\
\hline M-ChE-2-s & 25 & 27 & 15 & 7 & 6 & 4 & 9 & 1 & 1 & & 6 & 232 & 66 \\
\hline M-EE-3-s & 24 & 30 & 19 & 6 & 5 & 2 & 5 & 4 & 1 & & 2 & 134 & 32 \\
\hline M-ME-4-s & 17 & 31 & 12 & 8 & 13 & 9 & 2 & 3 & 3 & & & 172 & 80 \\
\hline MEAN & 25.4 & 27.4 & 15.0 & 7.8 & 6.6 & 3.4 & 6.0 & 3.2 & 2.6 & & 2.0 & 180 & 61 \\
\hline
\end{tabular}

\begin{tabular}{lrrrrrrrrrrrrr} 
F-CE-4 & 37 & 23 & 4 & 9 & & 3 & 6 & 8 & 2 & 6 & 2 & 182 & 72 \\
M-ME-3 & 31 & 26 & 12 & 7 & 1 & 1 & 7 & 7 & & 3 & 3 & 139 & 38 \\
F-ME-4 & 28 & 30 & 15 & 5 & 2 & 2 & 1 & 7 & 3 & & 7 & 134 & 59 \\
M-GE-4 & 34 & 24 & 9 & 6 & 2 & 5 & 4 & 6 & 6 & 1 & 3 & 218 & 69 \\
F-ME-3 & 27 & 42 & 4 & 8 & 2 & 3 & 2 & 6 & 6 & 1 & 1 & 114 & 42 \\
\hline MEAN & $\mathbf{3 1 . 4}$ & $\mathbf{2 9 . 0}$ & $\mathbf{8 . 8}$ & $\mathbf{7 . 0}$ & $\mathbf{1 . 4}$ & $\mathbf{2 . 8}$ & $\mathbf{4 . 0}$ & $\mathbf{6 . 8}$ & $\mathbf{3 . 4}$ & & $\mathbf{3 . 2}$ & $\mathbf{1 5 7}$ & $\mathbf{5 6}$ \\
\hline
\end{tabular}

Percentages were rounded to the nearest tenth.

\section{Meta-Cognition}

Phrases that were coded for metacognitive strategies concerned participants' awareness of their knowledge or their knowledge building strategies. Examples of meta-cognitive phrases are, "So this is based on the stuff I want to know about; what his limitations are" and "Technical description of prototypes. Oh, that might be helpful, that might explain some things.”

As can be seen from Table III, most of the SBL students in this sample had more phrases related to metacognitive strategies $(M=15 \%)$ compared to non-SBL students $(M=8.8 \%)$. Researchers view self-regulatory processes in terms of three cyclical phases, the first being the forethought phase. In addition to goal setting, the forethought phase involves strategic planning (SP) and task analysis (TA).

Comparing the forethought phase during the design process of two students, one SBL and the other non-SBL, it appears that the SBL sophomore demonstrated more sophisticated task 
analysis and strategic planning than did the non-SBL senior. For example, within the first few minutes of the design task, M-ChE-2-s voiced his strategic plan saying:

(The number shown in parenthesis is the time stamping in minutes: seconds.)

[01:19] First thing I'm just gonna look through all these cards and just figure out which way I'd like to first attack it. (SP)

[01:25] So talk to Jim ... I can get more detail about the disabilities that these people have and the best ways that they think they can solve the problem. (SP)

[01:37] Build a prototype. (That's) going to be a little later on, once I figure out the direction I wanna go in. (SP)

[01:48] Talk with Mary . . I'm gonna have to do at the start. (SP)

[02:37] So first I wanna talk with Jim . . figure out what problems they have with opening jars. (SP)

This student proceeded to deploy this last strategy by reading about the clients, Jim and Mary, and stating that he wanted to learn about them to better understand their disabilities. This student researched information which he thought was relevant and reached his interpretation of the problem, or task analysis within a half hour:

[24:25] I want something for the jar to be able to, be in . . to put the jar into something ... that would hold it. (TA)

[29:15] So the thing is about holding it still while turning. (TA)

M-GE-4 likewise incorporated strategic planning steps, but not to the extent of the first example. He did not explain why he picked the choices he did, but rapidly read through them.

[03:28] Review the first sources of physics, I would not. (SP)

[03:30] View the aesthetics, No. Plan, draw, sketch. No. (SP)

[03:42] Alright, first thing I'd probably do is, I would look at the jars that are currently here. (SP)

This student rapidly arrived at his interpretation of the problem:

[06:27] I'm not really worried about the bottom of the jar . . I'm more worried about the top of the jar and getting it off. (TA)

[09:00] You have to find a way to seal it down with perhaps like an o-ring or something that would . . . provide a seal 'cause jars are pretty much used for your liquid containment. (TA)

As stated previously, naïve self-regulators fail to monitor their performance or monitor haphazardly, and often rely on fragmentary information. M-GE-4 had an incorrect task analysis, or interpretation of the problem (sealing the jar as opposed to opening it) due to incomplete information. M-ChE-2-s wanted to learn about the clients first in order to plan his prototype. MGE-4 designed his prototype first, and as an afterthought said: 
[17:04] I'd probably want to talk to Jim and Mary... just to ensure that, that (using his prototype) is something that they can do.

After reading about the clients, this student realized his design would not work, saying,

[21:49] The problem with this prototype is that it requires redesigning jars in general ... you could talk to jar manufacturers of jars, see if you could get them to change their design.

This student demonstrated naïve task analysis and strategic planning skills, resulting in two incorrect interpretations of the problem (sealing the jar and then redesigning jars). He relied on fragmentary information, and learned about the clients only after designing his prototype.

Without appropriate task analysis and strategic planning, learners are unsure as to what to do next and can be more easily discouraged. This was demonstrated by F-CE-4. Although she had adequate skills in evaluating other prototypes, she had poor task analysis and planning strategies. At several junctures, she was perplexed in deciding her next steps:

[35:35] I don't know. I don't know if I'd talk to jar manufacturers. I don't know. I feel like I might talk to a jar manufacturer. I wouldn't know what to get out of it though.

[39:26] Or a ratchet? I wouldn't know how to build that though.

[48:21] I don't know, I guess like the whole gear thing. I can't just really picture in my head how it would all stick together.

[50:06] There's just a lot of wheels. So I'm wondering if I could use wheels somehow. I don't know.

Fifty minutes into the project, this student had yet to formulate a concept for a prototype because she was unable to clearly analyze the task or articulate a proper interpretation of the problem. Poor planning strategies and task analysis adversely affected this student's problem solving abilities for this task

Confusion

A striking difference between the two groups concerned the category of Confusion. While four out of five of the non-SBL students had phrases in this category, none of the SBL students did. Most of the comments in this category pertained to the clients' disabilities. The non-SBL participants had trouble comprehending, remembering, and addressing client limitations due to various physical challenges. For example, the information card clearly stated that there were upper-limb amputees who had trouble opening jars with one hand. The activity cards for the amputee client Jim also explicitly stated that he does NOT have a prosthetic arm. Yet some students still were not clear on this point and questioned what Jim was physically capable of. Naive self-regulators often do not use or recognize the knowledge they have, improperly apply it to the task at hand, or misinterpret the information entirely. Reading the "Talk to Jim" card, FCE-4 said:

[09:15] So, we won't know if his defects are physical or from his brain ... Ok. So he has both arms? 
One of the researchers explained that Jim was an amputee and had only one arm. A minute later this student again asks:

[14:28] So does Jim have the other arm, or like a mechanical one?

M-ME-3 similarly did not fully understand the information presented in the client cards and interpreted the information as:

[12:48] From what I gather from both of those (clients) is that they have weak limbs.

M-GE-4 also seemed to be confused about the definition of an upper-limb amputee:

[04:41] The major difficulties that they would probably have doing is coordinating two hands or using two hands if you're an amputee.

While building his model, this student commented:

[54:27] I'm making it specifically for them. They were lefties now, right?

The non-SBL students in this sample had difficulty understanding obvious limitations of the clients which were important for this particular design task. While the SBL students in this sample understood these limitations, many of the non-SBL students appeared unable to grasp the significance of these client characteristics.

\section{Discriminates Information}

With limited time, limited cognitive resources, and an abundance of information readily available, learners need to employ strategies to recognize extraneous information. Irrelevant information can decrease student performance ${ }^{56}$. Naive self-regulators often cannot tease out important from nonessential information, do not use the knowledge they have, improperly apply it to the task at hand, or misinterpret the information entirely.

The information cards included material that was totally irrelevant to the task as a mechanism to determine if students had the ability to discriminate useful from superfluous information. Examples of phrases discriminating information are, "Couldn't do math well. That doesn't really pertain to this" and "She didn't think she was having a stroke because she was young. Not all that relevant to what I need to design."

As can be seen from Table 2, students in this sample who had SBL experiences were better able to discriminate useful from irrelevant information $(\mathrm{M}=6.6 \%)$ compared to non-SBL students $(\mathrm{M}=1.4 \%)$. There were many unnecessary pieces of information that some of the nonSBL students did not recognize as such. For example, one of the cards mentioned tension and how it was unwise to tie up a boat in a storm with a steel chain. F-CE-4 commented:

[28:25] Don't use a steel chain! Um, so, hm, hm. I'll figure out what that means ... I just don't know how I would use tension in a twisting application. So I 
guess, in the lever arm, I'd like to make sure that the lever doesn't snap off.

This student was trying to utilize an irrelevant piece of information and was unable to recognize that it had no practical use for the design task at hand.

\section{Reflection}

There were observed differences between the two groups of students in the categories of Metacognition, Confusion, and Discriminates information. These differences emerged from the verbal protocols during the design task. Differences between the groups also emerged from the students' reflection papers.

The third cyclic phase of the self-regulatory processes is a self-reflection phase, which includes self-evaluation and comparing performance with goals. In general, the non-SBL students tended to focus on the outcome or the end product while the SBL students tended to write about themselves as cognizing agents. For example, M-GE-4 wrote:

I originally wanted to have two wrenches ... when I realized that with the jar locked to the ground . . . any amputee or stroke survivor would be able to open the jar.

\section{F-ME-3 wrote:}

I decided to use the rack and pinion technique to translate the rotational motion from the knob of the user interface into a linear motion, clamping the jar in place

... I basically just built ... a box that held the gears in place, a bearing to keep the arm from deflecting when the jar is turned, etc. . . . By placing a brick over the "bearing," it does a good job of holding it in place.

The SBL students tended to review their actual design process and commented more on their learning. For example, F-EnE-4-s wrote:

I liked having the different cards to reference to give me an idea of what considerations to make in my design and who exactly I was designing for. I think that the only cards I didn't look at were the ones about mechanics and basic physics because I felt that I already had enough understanding of those concepts ... . It was a little weird to talk aloud, just because I'm not used to doing that, however . . . it also probably helped me focus on the task since I was constantly reminding myself of the design goals.

M-EE-3-s similarly reflected on himself as a learner, and his design process:

It was a good experience to talk through an engineering design process . . . This forced me to be more introspective about my thoughts.

While the non-SBL students had a more objective perspective in their reflection papers by focusing on the final product, those with SBL experiences tended to be more introspective, regarding themselves as learners who were more aware of their metacognitive strategies. 


\section{DISCUSSION}

These results support previous research which found that students who participated in a problembased curriculum used more adaptive self-regulation strategies than students who participated in a more traditional curriculum ${ }^{57}$. Our sample of students who had been involved with SBL activities demonstrated more accurate task analysis/problem interpretation skills, better strategic planning skills, a clearer understanding of client limitations, and was better able to discriminate useful from irrelevant information, than our sample of students who had not had such experiences.

The first observed difference between the two groups was in the category of Metacognition. The SBL students with stronger metacognitive skills were more accurate in task analysis and more definitive in strategic planning. Solving well-defined problems in the classroom does not readily transfer to solving complex, ill-defined problems in the workplace, as the former requires cognitive and metacognitive processes that are insufficient for solving the latter ${ }^{18}$. During SBL field experiences, students are confronted with ill-structured, more complex problems, with multiple solutions and unexpected constraints and challenges ${ }^{58}$. These field experiences encourage students to analyze the task more intensely, to plan with a deeper understanding of the problem, and to dialogue and interact with other students, faculty, and clients. The intense interaction required to solve the real-world challenges they were confronted with enhanced their strategic planning and task analysis skills, which they demonstrated during this model-building engineering design task.

The second salient point that emerged from our data was the confusion of non-SBL students regarding the explicit characteristics of the client disabilities. As mentioned earlier, clients are central to the process and equal participants in a collaborative project. Whether working with inner-city elementary school children or building a water filtration system in a third world country, the SBL students had the experience of closely interacting with clients and building a meaningful relationship with them ${ }^{59}$. Those with international experiences often lived with the people they worked with, so students had an obligation to understand authentic client requirements and limitations. Their SBL experiences helped develop strong interpersonal skills in order to understand client needs, characteristics, and limitations. Students without SBL experiences were not as likely to have had the same in-depth client interactions and were therefore, not as aware of the importance of clients' needs and limitations in the design process.

The third major difference between the groups appeared in the category of Discriminating Information. Overall, the non-SBL students appeared less efficient at monitoring and applying information. Some tried to apply useless information to the task or were unable to recognize significant information. Real-world experiences offer learning challenges that are not readily confronted in the classroom. Traveling to a third world country has additional challenges of travel planning and coordination, fundraising issues, working collaboratively on multidisciplinary and multi-cultural teams, and arranging for material delivery across international borders. These make for unfamiliar situations that students are not confronted with in the classroom. In unfamiliar situations, learners need to reflect on discrepancies between what they think is true and new information that may not support that view ${ }^{33}$. Individuals must learn to filter out extraneous information and focus on the core information needed for the task at hand. This sample of students who had SBL experiences was better able to discriminate useful from irrelevant information. 
The forth point concerns the different perspectives the groups had regarding design task outcomes. Before we can develop metacognitive strategies, we must first be aware of ourselves as cognizing individuals with the ability to monitor our own learning strategies and adapt accordingly. Self-reflection, an inherent component of SBL activities, helps participants realize who they are and what they can achieve. This emerged in their reflection papers. The non-SBL students focused on their final product. Those with SBL experiences tended to be more introspective, regarding themselves as learners who were aware of their abilities as cognizing individuals.

There were differences in cognitive process between these two groups of students during this design task that cannot be attributed to different group levels of design experience. The design experience of this student sample varied considerably, however the SBL group did not have more experience than the non-SBL group. Four of the five non-SBL students were in either mechanical or civil engineering, disciplines that have traditionally been classified as more handson compared to chemical or electrical engineering. In fact, M-EE-3-s wrote in his reflection paper, “As an electrical engineer, problems like this are somewhat out of my discipline," and MChE-2-s similarly wrote that he was, "a chemical engineer not familiar with more mechanical designs." On the other hand, M-GE-4 talked about how much he liked to build things and play with robots saying, "This is like the type of stuff I love. I love doing this sort of stuff . . it's fun. It's something I enjoy . . . This is what an engineer at heart likes to do (and) is good at doing." So although there were individual differences in the level of design experience, one group did not appear to have more design experience than the other.

There is a growing awareness of the importance of helping students become more knowledgeable of and responsible for their own cognition and learning. In a revision of Bloom's taxonomy (a framework of educational objectives) Krathwohl included a new category of Metacognitive Knowledge, citing the importance of students being aware of their ability to manipulate their own thinking and learning ${ }^{60}$.

The metacognitive skill of self-reflection is clearly important and needs to be addressed more directly within engineering education. Lichtenstein et al. ${ }^{61}$ reported that engineering students, compared to students in other disciplines, had the lowest mean for Reflective Learning (e.g., examine the strengths and weaknesses of your own views) as well as Integrative Learning (e.g., discuss course ideas outside of class, discussions/assignments included diverse perspectives). Service-based learning experiences can help change this by offering students opportunities to reflect on their skills, decisions, and interactions on cross-disciplinary teams.

\section{CONCLUSION}

Understanding the cognitive process that go along with engineering design is important for implementing effective pedagogies for teaching design. Having good metacognitive skills is necessary in order to recognize the most effective and efficient manner to solve engineering design problems. This study demonstrates that these skills can be enhanced through SBL activities.

Because students self-select into SBL programs, it might be argued that these students already possessed more sophisticated self-regulated learning processes going into SBL programs. However, we posit it is their SBL experiences that instill more sophisticated metacognitive processes.

Our sample was limited in size and scope, and we do not suggest that the results generalize to all populations. Since we only had one SBL female in our sample, a future research direction 
would be to include more females in our sample and perhaps get a better understanding of why women are drawn to SBL experiences in higher numbers than in engineering overall ${ }^{2,3,15,25,26}$. A second direction is formatting the design task using a digital workbook supported by Robobooks ${ }^{\mathrm{TM}}$ software, which would allow for more widespread testing by other universities and using more participants. This is currently under way.

From our sample of students, it appears that engineering SBL activities can enhance the metacognitive processes of design for engineering students. Our sample of SBL participants had more sophisticated metacognitive abilities, better strategic planning and task analysis skills, was better able to discriminate useful from insignificant information, and had a better understanding of client needs and constraints. SBL activities offer participants a timely opportunity to be productive resources, able to utilize their skills and knowledge to problem solve in societal settings. For these reasons, we strongly suggest that engineering disciplines incorporate SBL activities into their curriculum.

\section{ACKNOWLEDGEMENTS}

This study was supported by the National Science Foundation's Innovations in Engineering Education, Curriculum, and Infrastructure Program, Grant No. EEC-0835981. Any opinions, findings and conclusions or recommendations expressed in this material are those of the authors and do not necessarily reflect the views of the National Science Foundation.

A special thanks to Chris Rogers for his invaluable input and ideas towards this project and for allowing the use of the Tuft's Center for Engineering Education and Outreach's resources during the writing of this manuscript.

\section{REFERENCES}

1. Accreditation Board for Engineering and Technology, www.abet.org, Assessed 8 November 2010.

2. L. Barrington and J. Duffy. Attracting underrepresented groups to engineering with service-learning, American Society for Engineering Education Annual Conference and Exposition, Honolulu, HI., 2007.

3. E. Coyle, L. Jamison, and W. Oakes. The EPICs engineering projects in Community Service, International Journal of Engineering Education, 21(1), 2005, pp. 1-12.

4. Learn and Serve Clearinghouse, http://servicelearning.org/what is service-learning/ servicelearning is/index.php, Assessed 10 April 2010.

5. A. Astin and L. Vogelgesang, Understanding the effects of service based learning: A Study of Students and Faculty, Higher Research Institute, University of California, Los Angeles, CA., 2006.

6. R. Bringle, M. Phillips, and M. Hudson, The Measure of Service Learning: Research Scales to Assess Student Experiences, American Psychological Association, Washington, DC, 2004.

7. B. Jacoby, Service-learning in today's higher education, in B. Jacoby (ed.) Service-Learning in Higher Education, pp. 3-25, Jossey Bass Publishers, San Francisco, CA., 1996.

8. J. Eyler and D. Giles, Where's the Learning in Service-Learning? Jossey-Bass Publishers, San Francisco, CA., 1999.

9. S. Mintz and G. Hesser, Principles of good practice in service-learning, in B. Jacoby (ed.) ServiceLearning in Higher Education, pp. 26-52, Jossey Bass Publishers, San Francisco, CA., 1996.

10. R. Simpson, The role of public service in young adult development: Highlights from recent research, MIT Public Service Center, 2009. 
11. C. Swan, K. Paterson, and A. Bielefeldt. Measuring the impacts of project-based service learning in engineering education, American Society for Engineering Education IEEE Frontiers in Education Conference, San Antonio TX., 2009.

12. A. Astin, L. Vogelgesang, E. Ikeda, and J. Yee. How service based learning affects students, Higher Education Research Institute, University of California, Los Angeles, CA., 2000.

13. Engineering Projects in Community Service, https://engineering.purdue.edu/ EPICS/, Assessed 8 March 2010.

14. Engineers for a Sustainable World, www.esustainableworld.org, Assessed 8 November 2010.

15. Engineers Without Borders, www.ewb-usa.org, Assessed 8 November 2010.

16. Service Learning Integrated Throughout a College of Engineering, slice.uml.edu Assessed 10 March 2010.

17. Student Teacher Outreach Mentorship Program, www.stompnetwork.org, Assessed 10 March 2010.

18. G. Schraw, M. Dunkle, and L. Bendixen, Cognitive Processes in Well-Defined and Ill-Defined Problem Solving, Applied Cognitive Psychology, 9(6), 1995, pp. 523-538.

19. P. Dutta and H. Alexander, Engineering design via team-based service based learning projects: Case survey of five unique project genres. American Society for Engineering Education Annual Conference and Exposition, Honolulu, HI., 2007.

20. L. Foote and J. DiFilippo, STEM literacy, civic responsibility, and future vision. Examining the effects of the Lawrence math and science partnership, in T. Kelshaw, F. Lazarus, and J. Minier (eds.) Partnerships for Service Based Learning: Impacts on Communities and Students, pp. 165-205, Jossey Bass Publishers, San Francisco, CA., 2009.

21. S. Lord, Service-Learning in Introduction to Engineering at the University of San Diego: First lessons, American Society for Engineering Education IEEEE Frontiers in Education Conference, San Juan, Puerto Rico, 1999.

22. C. Swan, D. Gute, D. Matson, and J. Durant, International community-based projects and engineering education: The advisor's viewpoint, American Society of Engineering Education Conference, Honolulu, HI., 2007.

23. C. Wigal, E. McMahon, and M. Littleton, Measuring the benefit of service oriented student design projects, American Society for Engineering Education IEEE Frontiers in Education Conference, Saratoga Springs, NY., 2008.

24. D. Prime and D. Rhine, Experiencing engineering while helping others: UMass Lowell's Assistive Technology Design Fair, in T. Kelshaw, F. Lazarus, and J. Minier (eds.) Partnerships for Service Based Learning: Impacts on Communities and Students, pp. 235-266, Jossey Bass Publisher, San Francisco, CA., 2009.

25. H. Matusovich, D. Follman, and W. Oakes, Work in Progress: A student perspective. Why women choose service learning. American Society for Engineering Education IEEE Frontiers in Education Conference, San Diego, CA. 2006.

26. National Center for Education Statistics, http://nces.ed.gov, Assessed 1 April 2010.

27. J. Flavell, Metacognition and cognitive monitoring. A new area of cognitive-developmental inquiry, American Psychologist, 34(10), 1979, pp. 906-911.

28. P. Pintrich, The role of metacognitive knowledge in learning, teaching, and assessing, Theory into Practice, 41(4), 2002, pp. 219-225.

29. B. Zimmerman, Becoming a self-regulated learner: An overview, Theory into Practice, 41(2), 2002, pp. 64-70.

30. D. Schunk and B. Zimmerman, Conclusions and future directions for academic interventions, in B. Zimmerman and D. Schunk (eds.) Self-regulated Learning. From Teaching to Self-reflective Practice, pp. 225-235, Guilford Press, New York, NY., 1998.

31. B. Zimmerman, A social cognitive view of self-regulated academic learning. Journal of Educational Psychology, 81(3), 1989, pp. 329-338. 
32. M. Bernard, Metacognition-What a cognitive system may/should know about itself, in C. Forsythe, M. Bernard, and T. Goldsmith (eds.) Cognitive Systems: Human Cognitive Models in Systems Design, pp. 285-300, Lawrence Erlbaum, Mahwah, NJ, 2006.

33. H. Everson and S. Tobias, The ability to estimate knowledge and performance in college: A metacognitive analysis, Instructional Science, 26(1), 1998, pp. 65-79.

34. M. Carr, The Importance of metacognition for conceptual change and strategy use in mathematics, in H. Salatas Watere and W. Schneider (eds.) Metacognition, Strategy Use and Instruction, pp. 176-200, Guilford Press, New York, NY, 2010.

35. D. Schunk, Social Cognitive theory and self-regulated learning, in B. Zimmerman and D. Schunk (eds.) Self-regulated Learning and Academic Achievement, pp. 125-152. Lawrence Erlbaum Associates, Mahwah, NJ, 2001.

36. B. Zimmerman, Developing self-fulfilling cycles of academic regulation: An analysis of exemplary instructional models, in B. Zimmerman and D. Schunk (eds.) Self-regulated learning. From teaching to self-reflective practice, pp. 1-17. Guilford Press, New York, NY, 1998.

37. B. Zimmerman and D. Schunk, Reflections on theories of self-regulated learning and academic achievement, in B. Zimmerman and D. Schunk (eds.) Self-regulated Learning and Academic Achievement, pp. 289- 307, Lawrence Erlbaum Associates, Mahwah, NJ., 2001.

38. C. Atman and K. Bursic, Verbal protocol analysis as a method to document engineering students design processes, Journal of Engineering Education, 87(2), 1998, pp. 121-131.

39. N. Cross, Design cognition: Results from protocol and other empirical studies of design, in C. Eastman, W. McCracken, and W. Newstetter. (eds.) Design Knowing and Learning: Cognition in Design Education, pp. 79-104, Elsevier Science Ltd., Oxford, UK, 2001.

40. K. Dorst and N. Cross, Protocol Analysis as a Research Technique for Analyzing Design Activity, Design Engineering Technical Conference, Delft, the Netherlands, 1995.

41. K. Ericsson and J. Smith, Prospects and limits of the empirical study of expertise: An introduction, in K. Ericsson and J. Smith (eds.) Toward a General Theory of Expertise, Cambridge University Press, New York, NY., 1991.

42. C. Atman, M. Cardella, J. Turns, and R. Adams, Comparing freshman and senior engineering design processes: An in-depth follow-up study, Design Studies, 26(4), 2005, pp. 325-357.

43. K. Bursic and C. Atman, Information gathering: A Critical step for quality in the design process, Quarterly Management Journal, 97(4), 1997, pp. 60-75.

44. C. Mullins, C. Atman, and L. Shuman, Freshman engineers' performance when solving design problems, IEEE Transactions on Education, 42(4), 1999, pp. 281-287.

45. D. Radcliffe and T. Lee, Design methods used by undergraduate engineering students, Design Studies, 10(4), 1989, pp. 199-207.

46. C. Atman, R. Adams, M. Cardella, J. Turns, S. Mosborg, and J. Saleem, Engineering design processes: A comparison of students and expert practitioners, Journal of Engineering Education, 96(4), 2007, pp. 359-379.

47. H. Christiaans and K. Dorst, Cognitive models in industrial design engineering: A protocol study, Design Theory and Methodology, 42(1), 1992, pp. 131-137.

48. C. Ennis and S. Gyeszly, Protocol analysis of the engineering systems design process, Research in Engineering Design 3(1), 1991, pp. 15-22.

49. K. Ericsson and H. Simon, Protocol Analysis: Verbal Reports as Data (2nd ed.), MIT Press, Cambridge, MA., 1993.

50. K. Ericsson and H. Simon, Verbal reports as data. Psychological Review, 87(3), 1980, pp. 215-251.

51. A. Fontana and J. Frey, The interview: From neutral stance to political involvement, in N. Denzin and Y. Lincoln (eds.) The Sage Handbook of Qualitative Research, pp. 695-727, Sage Publications, Thousand Oaks, CA., 2005. 
52. N. Denzin and Y. Lincoln, Methods of collecting and analyzing empirical materials, in N. Denzin and Y. Lincoln (eds.) The Sage Handbook of Qualitative Research, pp. 641-649, Sage Publications, Thousand Oaks, CA., 2005.

53. G. Lemons, A. Carberry, C.Swan, C. Rogers, and L. Jarvin, The Benefits of Model Building in Teaching Engineering Design, Design Studies, 31(3), 2010, pp. 288-309.

54. M. Patton, Qualitative Research and Evaluation Methods, Sage Publications, Thousand Oaks, CA., 2002.

55. J. Creswell, Qualitative Inquiry and Research Design: Choosing Among Five Traditions, Sage, Thousand Oaks, CA., 1998.

56. R. Mayer, Fostering scientific reasoning with multimedia instruction, in H. Salatas Watere and W. Schneider (eds.) Metacognition, Strategy Use, and Instruction, pp. 160-175, Guilford Press, New York, NY., 2010.

57. B. Galand, B. Raucent, and M. Frenay, Engineering students' self regulation, study strategies, and motivational beliefs in traditional and problem-based curricula, International Journal of Engineering Education, 26(3), 2010, pp, 523-534.

58. D. Jonassen, J. Strobel, and C. Lee, Everyday problem solving in engineering: Lessons for engineering educators, Journal of Engineering Education, 95(2), 2006, pp. 139-151.

59. A. Bielefeldt, K. Paterson, and C. Swan, Measuring the Value Added to Service Learning in ProjectBased Engineering Education, International Journal of Engineering Education, 25(3), 2010, pp. 535546.

60. D. Krathwohl, A Revision of Bloom's Taxonomy: An overview, Theory into Practice, 41(1): 2002, pp. 212-218.

61. G. Lichtenstein, A. McCormick, S. Sheppard, and J. Puma, Comparing the undergraduate experience of engineers to all other majors: Significant differences are programmatic. Journal of Engineering Education, 99(4), 2010, pp. 305-317. 